\title{
La lucha del movimiento social católico en contra del matrimonio igualitario en Colombia: un medio para legitimar el estilo de vida católico (2009-2015)
}

\author{
The Struggle of the Catholic Social Movement against \\ Same-sex Marriage in Colombia: A Means to Legitimize \\ the Catholic Life Style (2009-2015) \\ A luta do movimento social católico contra do casamento \\ igualitário na Colômbia: um meio para legitimar o estilo \\ de vida católico (2009-2015)
}

\section{Lina Malagón Penen}

FECHA DE RECEPCIÓN: 16 de AGOSTO de 2017. FECHA DE APROBACIÓN: 13 DE ABRIL DE 2018

DOI: http://dx.doi.org/10.12804/revistas.urosario.edu.co/sociojuridicos/a.6000

Para citar este artículo: Malagón Penen, L. (2018). La lucha del movimiento social católico en contra del matrimonio igualitario en Colombia: un medio para legitimar el estilo de vida católico (2009-2015). Estudios Socio-Jurídicos, 20(2), 129-163. doi: http://dx.doi.org/10.12804/revistas.urosario.edu.co/sociojuridicos/a.6000

\section{RESUMEN}

Partiendo del análisis de expedientes judiciales, de actas parlamentarias y de entrevistas semiestructuradas, este artículo de investigación busca contribuir al estudio de la influencia que el contramovimiento católico conservador colombiano ha ejercido sobre la formulación de las normas jurídicas, así como al de las razones que explican su interés por la legislación relativa a la familia. Para ello, en una primera parte, se muestra que, entre 2009 y 2015 , la movilización en contra del reconocimiento de la igualdad de las parejas conformadas por personas del mismo sexo fue organizada por católicos integristas que defienden un Estado confesional y por laicos intransigentes que actúan de conformidad con su deber religioso de evangelizar el derecho. En una segunda parte, luego de demostrar que el modelo católico de la familia sobrevivió al proceso formal de laicización del derecho civil, se demuestra cómo algunos activistas se opusieron al matrimonio igualitario para asegurarse

* Docente del Departamento de Derecho Constitucional de la Universidad Externado de Colombia, Bogotá D. C. y estudiante de doctorado en la Universidad Panthéon-Assas. Este paper fue presentado en 2017 en el congreso la asociación L\&S y hace parte de una investigación más amplia sobre el uso de la justicia constitucional por los movimientos sociales LGBT y católicos franceses y colombianos. Correo electrónico: lina.malagon@uexternado.edu.co. ORCID://orcid. org/0000-0003-1633-5668. 
de que la legislación civil no se desligara de dicho modelo y, por esta vía, garantizar la dominación y la supervivencia de su estilo de vida.

Palabras clave: catolicismo, matrimonio igualitario.

\section{ABSTRACT}

Based on the analysis of judicial files, parliamentary acts and semi-structured interviews, this paper seeks to contribute to the study of the influence exerted by the Colombian Catholic conservative countermovement over the formulation of legal norms, as well as the reasons behind its interest in family legislation. To achieve these goals, first, we show that, between 2009 and 2015, mobilization against equality for same-sex couples was organized by Lefebvristes defending the establishment of a state with official religion and by intransigent lay people acting in accordance with their religious duty to evangelize law and ensure its conformity with the divine natural law. Secondly, after demonstrating that the Catholic family model survived the formal process of secularization of civil law, we show that the activists fought against same-sex marriage to guarantee the domination and survival of Catholic lifestyle trough ensuring law didn't become detached from the traditional family structure.

Keywords: catholicism, same-sex marriage.

\section{RESUMO}

Partindo da análise de expedientes judiciais, de atas parlamentárias e de entrevistas semiestruturadas, este artigo de pesquisa busca contribuir ao estudo da influência que o contramovimento católico conservador colombiano tem exercido sobre a formulação das normas jurídicas, assim como das razões que explicam sei interesse pela legislação relativa à família. Para isso, em uma primeira parte, se mostra que, entre 2009 e 2015, a mobilização contra o reconhecimento da igualdade dos casais conformados por pessoas do mesmo sexo foi organizada por católicos integristas que defendem um estado confessional e por laicos intransigentes que atuam de conformidade com seu dever religioso de evangelizar o direito. Em uma segunda parte, depois de demonstrar que o modelo católico da família sobreviveu ao processo formal de laicização do direito civil, se demonstra como alguns ativistas se opuseram ao casamentos igualitário para se assegurar de que a legislação civil não se desligara de dito modelo e, por esta via, para garantir a dominação e a supervivência de seu estilo de vida.

Palavras- chave: catolicismo, casamento igualitário. 


\section{Introducción}

Desde principios de la década de 2000, cuando en Colombia se discutió sobre la posibilidad de reconocer la existencia jurídica de las parejas del mismo sexo (en adelante PMS), algunos sectores conservadores reaccionaron para defender un modelo tradicional de familia (Lehoucq, 2017; Malagón Penen, 2015). Tal y como ha sucedido en otros países de América Latina (Morán Faúndes, 2012a; 2012b; Vaggione, 2009a; 2009b), el catolicismo ha liderado la oposición al reconocimiento jurídico de las familias conformadas por personas LGBT a través de activistas y organizaciones que, aunque tienen estrechas relaciones con esa religión, muchas veces intervienen en los asuntos políticos como simples ciudadanos o como simples funcionarios públicos usando argumentos seculares, hechos que dificultan la comprensión sobre la influencia que esa religión ha tratado de ejercer sobre la formulación de las normas jurídicas.

Y, si bien en Colombia existe un contramovimiento católico que se ha movilizado en la arena pública para evitar cambios en las normas jurídicas relativas al matrimonio y a las relaciones paternofiliales, existen pocas investigaciones sobre ese tema (Albarracín \& Lemaitre, 2016; Lemaitre, 2012; Lemaitre Ripoll, 2010; 2013).

En ese contexto, para contribuir al estudio de ese movimiento social, en una primera parte mostraré que, entre 2009 y 2015 aunque la jerarquía de la Iglesia católica intervino muy poco públicamente, la oposición católica al reconocimiento jurídico de la igualdad entre PMS y parejas conformadas por un hombre y una mujer fue llevada a cabo por laicos intransigentes y por católicos integristas quienes defendieron el modelo católico de la familia en las arenas judicial y legislativa (1). En una segunda parte, luego de explicar que, gracias al poder cultural del catolicismo, dicho modelo de familia pudo sobrevivir al proceso de secularización formal del derecho civil, me enfocaré en demostrar que muchos de los activistas católicos defienden la legislación civil tradicional relativa al matrimonio y a la filiación para asegurarse de que el derecho legitime la antropología religiosa según la cual el hombre tiene una naturaleza humana que limita su voluntad. En este sentido, mostraré que, partiendo de la creencia de que el derecho tiene una dimensión simbólica, muchos de los participantes del contramovimiento católico quieren asegurarse 
de que la antropología religiosa siga siendo validada por el derecho para garantizar la supervivencia del estilo de vida basado en los valores del catolicismo. En efecto, como la apertura jurídica del matrimonio y de la filiación a las PMS supone que el derecho civil se desligue del modelo católico de la familia, esta es interpretada como una manifestación del proceso de exculturación del catolicismo que pone en peligro a la religión católica (2).

Desde el punto de vista metodológico, este artículo de investigación está basado en dos fuentes principales de información. Por un lado, debido a que la investigación se centró en el sistema de creencias de algunos participantes del contramovimiento, entre abril y julio del año 2013 realicé seis entrevistas semiestructuradas a altos dirigentes de tres organizaciones católicas que se opusieron al reconocimiento de las PMS en la Corte Constitucional y/o en el Congreso de la República entre los años 2002 y 2015 y que, por lo tanto, fueron informantes clave (Blee E Taylor, 2002) ${ }^{1}$. A través de esas entrevistas, pude recopilar datos: i) sobre las razones que explican la oposición de los militantes al reconocimiento jurídico de las PMS; y ii) sobre las organizaciones católicas que intervinieron ante el Congreso de la República y/o ante la Corte Constitucional para defender el modelo tradicional de la familia. Por otro lado, la investigación supuso un trabajo documental centrado en el análisis de fuentes primarias pues, para recopilar información e identificar a los activistas católicos, analicé los expedientes judiciales de la Corte Constitucional relacionados con el matrimonio y la adopción por parte de $\mathrm{PMS}^{2}$, así como las actas parlamentarias de la audiencia pública y de la sesión libre organizadas en el marco del Proyecto de Ley No. 047 de 2011 (Cámara) por medio del cual se pretendió abrir el matrimonio a las PMS (Imprenta Nacional de Colombia, 2013a; 2013b). 


\section{Laicos intransigentes y lefebvristas comprometidos con la defensa del modelo católico de la familia}

Partiendo de estudios empíricos que muestran que las creencias religiosas generan la participación de algunos católicos en el espacio público (Duriez, 2000; Frölich, 2002; Hertzke, 1988; Krishnan E Dulk, 2014; Smith, 1996), y teniendo en cuenta que el catolicismo no es un bloque homogéneo sino un universo compuesto por múltiples corrientes (Arias, 2003; Donegani, 1993; Frölich, 2002; Hervieu-Léger \& Champion, 2008; Pelletier \& Schlegel, 2012), es necesario precisar que, aunque la jerarquía de la Iglesia católica intervino muy pocas veces en los procesos constitucionales estudiados, y no intervino en las audiencias organizadas en el Congreso, la oposición católica a la apertura del matrimonio y de la filiación a las PMS fue llevada a cabo por militantes que entran en las categorías de laicos intransigentes que evangelizan la política ${ }^{3}$, o de católicos integristas o lefebvristas que defienden el establecimiento de un estado confesional ${ }^{4}$.

En ambos casos, el detonante de su militantismo fue la defensa del modelo católico de la familia: todos los participantes del contramovimiento analizado se movilizaron ante la Corte Constitucional y ante el Congreso de la República para preservar la familia fundada en el matrimonio de un hombre y una mujer.

Para entender las categorías de militantes es necesario saber que, a partir de la Revolución francesa, advino la modernidad liberal que se caracteriza por rechazar las verdades reveladas y adoptar el principio de separación entre la Iglesia y el Estado en función del cual no solo se debe respetar la libertad de conciencia y de religión sino que, además,

3 Según los cánones 204 a 207 del Código de Derecho Canónico, la Iglesia está compuesta por fieles, es decir, por toda la comunidad de bautizados que incluye a los laicos y al clero. Los laicos son entonces todas aquellas personas que fueron bautizadas según el rito católico, pero que no recibieron el sacramento de la ordinación.

4 Si bien los lefebvristas se califican a sí mismos como católicos tradicionalistas, en el marco de este artículo preferimos designarlos mediante la expresión de católicos integristas en la media en que ya no hacen parte de la Iglesia católica y los autores que los estudian los denominan de esa manera. Sin embargo, no usamos la expresión como sinónimo de fundamentalismo religioso (Frölich, 2002; Michel, 2009). 
las creencias religiosas deben ser relegadas al campo de la vida privada (Arias, 2003; Frölich, 2002; Poulat, 1982).

Frente a los desafíos que esta ideología representa para una religión que tiene pretensiones de universalidad, desde el siglo XIX el catolicismo se mueve entre una actitud de compromiso ("transigentismo") y una actitud de rechazo ("intransigentismo") hacia las ideas de la modernidad que ha dado lugar a diversas corrientes de pensamiento al interior del catolicismo y a distintas maneras de ser católico (Airiau, 2009; Arias, 2003; Frölich, 2002; Mayeur, 1972; Poulat, 1977; 1982; 1986; Theobald, 2009).

En lo relativo a este último punto, mientras que los católicos transigentes quieren adaptar sus creencias religiosas a la modernidad al reconocer un lugar al libre albedrío -sobre todo en el ámbito sexual-, los intransigentes se caracterizan por su voluntad de poner todo el catolicismo en todos los aspectos de su vida de manera que, en los temas relativos a la moral sexual, creen en las enseñanzas del magisterio romano (Airiau, 2000; Frölich, 2002).

En lo que se refiere a las corrientes del pensamiento, aunque algunos autores consideran que el Concilio Vaticano II marcó una ruptura con el intransigentismo; siguiendo la postura mayoritaria de los sociólogos e historiadores franceses, en este artículo se parte de la base de que la normatividad romana siempre ha acogido las ideas intransigentes aunque en diferentes grados en función del periodo histórico (Frölich, 2002; Hervieu-Léger, 2003; Poulat, 1977; 1982; 1986)5 .

Así, a lo largo del siglo XIX y durante una buena parte del XX, al creer que las ideas de la modernidad eran contrarias a su modelo de cristiandad, la jerarquía católica asumió una posición abiertamente intransigente al incitar a sus fieles a mantener, sin ningún compromiso, los principios del catolicismo y al condenar, entre otros, la separación entre el Estado y la Iglesia (Frölich, 2002; Mayeur, 1972; Poulat, 1982; Theobald, 2009).

5 El Vaticano II fue un concilio ecuménico y pastoral convocado por el papa Juan XXIII, en 1959, para tratar de reformular la doctrina católica y adaptarla a las necesidades y métodos "de nuestro tiempo". En él participaron 2400 obispos del mundo entero y no solamente de Europa quienes, entre 1962 y 1965, produjeron, varios documentos importantes como la constitución dogmática Lumen Gentium sobre la Iglesia, la declaración sobre la libertad religiosa Dignitatis $\mathrm{Hu}$ manae y la constitución pastoral Gaudium et Spes, sobre las especificidades del mundo moderno (la cultura, la familia y el matrimonio, la vida socioeconómica) (Frölich, 2002). 
Al oponerse a la libertad de conciencia y de religión, la jerarquía intentó, entonces, reconquistar la sociedad a través de la defensa de Estados con religión oficial. Sin embargo, debido a las dificultades prácticas encontradas para llevar a cabo ese proyecto político en los países secularizados o en aquellos en los que el catolicismo era minoritario, a partir de la Segunda Guerra Mundial el magisterio romano empezó a adoptar una estrategia más discreta pero igualmente intransigente (Hervieu-Léger, 2003; Moyn, 2015; Portier, 2005).

Según esta nueva postura, en principio (tesis), el objetivo era imponer el catolicismo como religión oficial; pero en aquellos países en los que era imposible llegar a ese ideal, la Iglesia podía tener en cuenta la realidad de las cosas y hacer algunos compromisos como aceptar la separación entre el Estado y la Iglesia siempre y cuando se respetara la autonomía de la institución católica (hipótesis) (Avon, 2016; Comte, 1998; Latala E Rime, 2009; Moyn, 2015; Portier, 2005).

Posteriormente, durante la Guerra Fría, debido a la consolidación de la Unión Soviética que fue muy hostil hacia las religiones y basándose en las ideas de filósofos católicos como Jacques Maritain, en un ambiente especialmente tenso marcado por la oposición de los más intransigentes como monseñor Marcel Lefebvre, el Concilio Vaticano II aprobó la declaración Dignitatis Humanae por medio de la cual se abandonó el esquema de la tesis/hipótesis y se reconoció la libertad de conciencia y de religión (Moyn, 2015).

Por consiguiente, el Vaticano II aceptó la separación entre la Iglesia y el Estado (1965) pero no abandonó el "intransigentismo", pues señaló que la Iglesia debe ejercer una vigilancia sobre la actividad del Estado que es únicamente legítima si es conforme con el derecho natural divino (Krishnan \& Dulk, 2014; Vatican II, 1965). En otras palabras, aunque el magisterio romano aprecia el sistema democrático y usa el vocabulario de los derechos fundamentales y humanos, no respeta la idea moderna de la autonomía de la política respecto a la Iglesia, pues la jerarquía católica reproduce el esquema medieval según el cual la legitimidad del ordenamiento jurídico depende de su conformidad con el iusnaturalismo divino (Médevielle, 2009; Portier, 1986).

Paralelamente, el Vaticano II revalorizó el lugar y el papel de los laicos cuya misión principal consiste en difundir el mensaje de Jesucristo. Ese 
deber religioso se predica, especialmente, en el campo de la política, de manera que los laicos tienen la obligación religiosa de difundir la concepción cristiana del mundo al usar, por un lado, todos los mecanismos disponibles de participación democrática y, por otro, en el caso de ser políticos o funcionarios públicos, al ejercer sus funciones de conformidad con la doctrina de la ley natural (Congrégation pour la doctrine de la doi, 2002, núm. 1; Vatican II, 1964; 1965)6.

Esto significa que, al aceptar su separación del Estado y por causa del paradigma de la secularización -que, de acuerdo con Vaggione, ha dado lugar a un discurso dominante según el cual los argumentos religiosos son irracionales y la participación política de las iglesias en la creación e interpretación del derecho es antidemocrática porque es concebida como una manifestación de ausencia de autonomía del Estado frente a la religión (2005b; 2005a; 2009b; 2009a) - desde el Vaticano II, la jerarquía católica trata de evangelizar la política principalmente a través de la acción de los laicos.

En este sentido, es necesario precisar que, en el campo del matrimonio y de la adopción igualitarias, muchos de los laicos católicos que se movilizaron en el Congreso y ante la Corte Constitucional actuaron como ciudadanos y no como representantes de organizaciones relacionadas con el catolicismo7. De manera similar, muchos otros lo hicieron en

6 Para el catolicismo, la vida humana es un don de Dios de manera que no le pertenece al hombre. Como el ser humano no puede gobernarse a sí mismo, debe seguir los mandamientos divinos que se expresan en la naturaleza que Dios le imprimió cuando lo creó y que puede descubrir por medio de su razón. Con base en la filosofía de Santo Tomás, esas reglas de conducta son definidas como la ley natural que es una norma ética fundamental y objetiva que permite a las personas ser verdaderamente humanas al diferenciar lo bueno de lo malo, lo falso de la verdadero, lo justo de lo injusto, etc. (Commission Théologique Internationale, 2008).

7 Por ejemplo, en el marco de la audiencia pública celebrada el $1^{\circ}$ de noviembre de 2012 en el marco del Proyecto de Ley No. 47 de 2011 (Cámara), el señor Corsi Otálora no intervino en su calidad de miembro fundador de Laicos por Colombia pero en su calidad de antiguo senador (Imprenta Nacional de Colombia, 2013a).

Además, ni Jorge Orlando García Norato, ni Jennis Ann Cubillos, ni Silfrido Baena González, ni Miller Rodríguez Góngora intervinieron como miembros del Centro de Ética y Humanidades de la Universidad la Gran Colombia (Imprenta Nacional de Colombia, 2013a), fundado por el señor Corsi Otálora.

En igual sentido, Hernando Salcedo Tamayo participó en la audiencia, en tanto que ciudadano sin identificarse, como abogado de la fundación católica provida Red Futuro Colombia (Imprenta Nacional de Colombia, 2013a).

Finalmente, aunque hace parte del grupo católico Centro Cultural Cruzada, Luis Fernando 
nombre de organizaciones que, si bien tienen una clara matriz católica, se presentan a la opinión pública como aconfesionales.

A pesar de que muchos no se identificaron como activistas católicos, pudimos determinar que pertenecen a organizaciones próximas al catolicismo. Siguiendo lo dispuesto en los cánones 297 a 303 del Código de Derecho Canónico que regulan el derecho de los fieles católicos a asociarse para contribuir a la misión de la Iglesia, esas estructuras presentan formas y características diferentes.

A excepción de la Universidad de la Sábana, que es una obra de apostolado corporativo de la prelatura personal del Opus $\mathrm{Dei}^{8}$, las demás son asociaciones de fieles. Dentro de esta última categoría hay que diferenciar las públicas de las privadas, las que tienen estatuto oficial y las de hecho (Conférence des évêques catholiques du Canada, 1993).

Así, el Consejo Nacional de Laicos de Colombia es una asociación pública reconocida por la Conferencia Episcopal. Esto significa que fue erigida por un acto jurídico de la Iglesia en el que se le reconoció personalidad jurídica y se le confió un mandato formal y público para desarrollar su misión que, en todo caso, se cumple en nombre de la Iglesia católica (Código de Derecho Canónico, 2017, sec. Cann. 298-302; Consejo Nacional de Laicos de Colombia, s.f.) ${ }^{9}$.

De manera similar, la Asociación Colombiana de Juristas Católicos fue fundada en el año 2009 con el objetivo de "estudiar el concepto católico del derecho [,] difundir la concepción política y jurídica del catolicismo en la sociedad [y] tener una incidencia, pronunciarse y controlar, por todos los medios posibles, especialmente los judiciales, la defensa de la

Escobar Duque intervino ante el Senado en su calidad de ciudadano colombiano (Imprenta Nacional de Colombia, 2013a).

8 Esta organización, que se implantó en Colombia en el año 1951 (Opus Dei, 2015) y que fue fundada por san José María Escrivá de Balaguer en Madrid, en 1928, encarna plenamente la idea del catolicismo integral, competente y presente en todos los campos que defiende el Vaticano II. En efecto, la ideología intransigente del Opus empuja a los hombres y a las mujeres católicos a buscar la santidad y el apostolado en el mundo en el que viven, es decir, en las actividades diarias que desarrollan en tanto miembros de familia y de la sociedad. Por este motivo, en 1979, Juan Pablo II afirmó que la obra anticipó la teología del laicado que caracteriza a la Iglesia desde el Vaticano II (Frölich, 2002).

9 Dicha misión es "ser puente de legitimación, apoyo y acompañamiento del laicado colombiano a la luz del Evangelio, sirviendo como fermento de fe y compromiso para la construcción del Reino de Dios con su Justicia" (Consejo Nacional de Laicos de Colombia, s.f.). 
perenne doctrina del magisterio de la Iglesia católica" (Cámara de Comercio de Bogotá, 2014a, p. 1). Esta asociación también es reconocida por esa institución pues este es un requisito exigido para poder denominarse con la palabra "católicos" (Código de Derecho Canónico, 2017, párr. 1. Cann 316).

Según su blog, "la cultura y los escenarios jurídicos deben ser permeados de las nociones tradicionales de derecho y política y orientados sin excepción por los postulados del derecho natural y católico" (ACJC, 2013). Hace parte de la Unión Internacional de Juristas Católicos, una asociación privada internacional de fieles reconocida por la Santa Sede, aunque próxima al integrismo católico que se creó en 1986 en París para contribuir "al mantenimiento o a la introducción de los principios cristianos en la filosofía y en la ciencia del derecho, en la actividad legislativa, judiciaria y administrativa, en la enseñanza y en la investigación así como en la vida pública y profesional" (CathoJuris, 2005).

Adicionalmente, también se movilizaron miembros de dos asociaciones de fieles sin estatuto oficial en la Iglesia y que son abiertamente católicas: Laicos por Colombia (en adelante LC) y la Fundación Cultura de la Vida Humana (en adelante FCVH) ${ }^{10}$. Cabe destacar que LC fue fundada en 1991 para "evangelizar la política" (Martínez, 2002, p. 81) luego de que la nueva Constitución señalara que Colombia es un país aconfesional en el que no hay religión oficial. Aunque en un principio fue un partido político, desde el año 2003 es una organización no lucrativa que defiende la idea de que "el cristianismo debe evangelizar la totalidad de la existencia humana, incluida la dimensión política. Critica por esto a quienes tienden a reducir el espacio de la fe a la vida personal o familiar. En efecto, la necesidad de la presencia de la Iglesia en lo político

10 Esta última organización fue fundada en 1997 con el objetivo de "cultivar, promover y defender la vida humana (...) de acuerdo con la ley natural y la ley de Dios" (Cámara de Comercio de Bogotá, 2014b). En el campo que nos interesa, esta organización apoya "el fortalecimiento de la familia como célula fundamental de la sociedad" (Cámara de Comercio de Bogotá, 2014b, p. 1).

Cabe resaltar que está aliada a la organización provida católica más grande del mundo, Human Life International, que fue fundada en 1981 para defender la vida humana desde la concepción hasta la muerte natural, esto es, "para dar gloria a Dios promoviendo la Vida, la Fe y la Familia" (Human Life International, s.f.). 
proviene de lo más íntimo de la fe cristiana: del señorío de Cristo que se extiende a toda la vida" (Martínez, 2002, p. 12) ${ }^{11}$.

Finalmente, también participaron miembros de dos asociaciones de fieles sin estatuto oficial en la Iglesia que se describen como aconfesionales aunque están compuestas, en su mayoría, por organizaciones y personas próximas al catolicismo: el Foro Nacional de la Familia (FNF) y la Fundación Marido y Mujer (FMM), creadas luego de que, en el año 2011, la Corte Constitucional incluyera a las PMS en el concepto de la familia constitucionalmente protegida (Malagón Penen, 2015).

Efectivamente, después de la promulgación de la sentencia C-577 de 2011, según unos de sus miembros, el FNF "se fundó porque (...) hoy en día, en los Estados democráticos (...) se quiere (...) redefinir el concepto de familia [y esa] redefinición (...) dinamita el núcleo de la sociedad" (Henao, 2013). En este mismo sentido, la FMM fue creada en junio de 2013 por un antiguo seminarista para "reconocer que la familia [es] la que se integra entre el varón y la mujer y de la cual brotan los hijos". Por este motivo, según su fundador, su objeto social es "promover la institución de la familia, configurada por el padre, la madre y los hijos" sobre todo a través del uso de las acciones constitucionales (Suárez, 2013).

En lo que se refiere a la segunda categoría de militantes estudiados, es necesario saber que, aunque siguiendo a Frölich y a Hervieu-Léger, creo que el Vaticano II no puso fin al intransigentismo de la jerarquía católica, en la época posconciliar; para una parte de católicos tradicionalistas, liderada por monseñor Marcel Lefebvre, ese concilio y las reformas a las que dio lugar fueron herejías (Frölich, 2002; Hervieu-Léger, 2003).

Por causa de su férrea lucha contra el Vaticano II, la Iglesia terminó por excomulgar a Marcel Lefebvre, situación que produjo un cisma: se creó la Fraternidad Sacerdotal San Pío X que agrupa a los lefebvristas o católicos integristas y que no es reconocida por la jerarquía de la Iglesia

11 LPC, el CNLC y la FCVH son tres organizaciones que comparten muchos de sus miembros. Así, por ejemplo, Gladys Buitrago de Amaya y Marta Saíz de Rueda son miembros del órgano directivo de LPC (Cámara de Comercio de Bogotá, 2014c) y ambas se han desempeñado como presidentas de la FCVH (Expediente D-6362, s.f., p. 525-cuaderno 3; Fundación Cultura de la Vida Humana, s.f.)s/f. En este mismo sentido, Andrés Forero Medina y Gladys Buitrago de Amaya hacen parte de LPC y del CNLC (Cámara de Comercio de Bogotá, 2014c; Fundación Derecho a Nacer, s.f.; Gaudium Press, 2010). 
católica (Duriez, Fouilloux, Pelletier, G Viet-Depaule, 2005; Frölich, 2002; Michel \& Sesboüé, 2009).

Si la oposición de ese grupo de católicos se cristalizó en torno de la liturgia, el integrismo católico surgió, primordialmente, por un desacuerdo político con el Vaticano II. En efecto, el lefebvrismo le reprocha a ese concilio el haber adherido al liberalismo moderno al haber aceptado la libertad religiosa y, en consecuencia, al haber reconocido la separación entre el Estado y la Iglesia (Michel, 2009).

En otras palabras, el integrismo católico se traduce en un pensamiento de extrema derecha construido sobre la base del rechazo a la democracia liberal pues su objetivo es el de restaurar los Estados católicos de corte monárquico en los que no solo el derecho válido es aquel que sigue la ley natural sino que, además, el catolicismo es la religión oficial (M. Lefebvre, 1976, 1987; Michel, 2009). Siguiendo la postura anterior al Vaticano II, el lefebvrismo tiene entonces como proyecto político la recristianización la sociedad por medio de la intervención directa de la Iglesia en el aparato estatal (Favier, 2011; Waché, 2004).

Desde este punto de vista, el participante del contramovimiento religioso más activo en el uso de la justicia constitucional para oponerse a los derechos de las PMS fue una autoridad estatal: la Procuraduría General de la Nación que, bajo la dirección de Alejandro Ordóñez (ferviente lefebvrista), entre 2009 y 2016, estuvo capturada por católicos intransigentes cercanos al Opus Dei, como Ilva Myriam Hoyos Castañeda o Gabriel Mora Restrepo y por otros católicos integristas como Juan Carlos Novoa (Albarracín \& Lemaitre, 2016; Lemaitre Ripoll, 2013; Malagón Penen, 2015).

En efecto, aprovechando todos los recursos públicos que tuvo a su disposición, esa entidad usó sus facultades constitucionales y legales para defender la conformidad del derecho colombiano con el derecho natural divino en el ámbito de la familia (así como de la sexualidad y de la muerte) ${ }^{12}$.

Es decir que, siguiendo la postura minoritaria de una parte de la sociología de los movimientos sociales y de la ciencia política que rechaza

12 Para conocer las actuaciones de la PGN en el debate sobre los derechos de las parejas del mismo sexo, se puede consultar: Albarracín, M., E Lemaitre, J. (2016). 
la idea clásica de que los participantes de los movimientos sociales son actores sociales necesariamente dominados, excluidos y marginalizados de la política (Della Porta E Diani, 2006; Goldstone, 2003; Kitschelt, 1989; Kriesi, 2015; Luck \& Dechezelles, 2015; Meyer \& Tarrow, 1998; Sawicki, 2015; Tilly \& Tarrow, 2008), parto de la base de que la PGN, durante el tiempo que fue dirigida por Alejandro Ordóñez, a pesar de hacer parte del Estado, fue uno de los participantes del contramovimiento católico colombiano.

En efecto, tomando como base el papel que el actor colectivo desempeña y no su posición respecto al interior del Estado (Grossman $\mathcal{E}$ Saurugger, 2012), es necesario concluir que la oposición radical de la PGN al matrimonio igualitario así como a la despenalización del aborto y de la eutanasia (Dalén, 2011; Jaramillo \& Alfonso, 2008; Sandoval Rojas, 2015) no puede entenderse como una consecuencia del cumplimento de las funciones que la Constitución y la ley le asignaron a esa entidad. El papel que jugó la PGN en la defensa de la vida desde la concepción hasta la muerte natural y contra la igualdad jurídica entre heterosexuales y homosexuales solo tiene sentido en la medida en que se inscribe en una densa red informal de católicos intransigentes e integristas que comparten una identidad colectiva específica según la cual el derecho tiene que ser conforme a la ley natural (Della Porta \& Diani, 2006; Malagón Penen, 2015).

Una vez demostrado que, en Colombia, el contramovimiento católico se opuso al matrimonio igualitario principalmente a través de la movilización de laicos intransigentes y de católicos integristas, a continuación, a partir de los planteamientos teóricos de Hervieu-Léger (2003) y del análisis del discurso formulado por varios de los activistas, trataré de evidenciar que la defensa de la familia, fundada en el matrimonio civil entre un hombre y una mujer, es muy importante para el catolicismo estudiado porque los militantes y la jerarquía consideran que el derecho tiene una dimensión simbólica que legitima una determinada visión del hombre. Desde esta perspectiva, asegurarse de que el derecho reproduzca el modelo católico de la familia es considerado como un medio para garantizar la dominación y la supervivencia del catolicismo. 


\section{La defensa del modelo católico de la familia como medio para legitimar la visión católica del hombre}

Para entender las razones simbólicas que empujaron a los militantes estudiados a defender el modelo católico de la familia, es necesario saber que Colombia hace parte de los territorios de "catolicidad" (Lefebvre, Béraud, E Meunier, 2015; Poulat, 1980): es un país en el que el catolicismo constituye "una institución cultural que ha marcado profundamente la lengua, la política, el espacio y el tiempo de la sociedad global" (Willaime, 2012, p. 309).

En efecto, en Colombia, la influencia del catolicismo ha sido particularmente importante puesto que, desde la Colonia y hasta finales de la década de los cincuenta, la Iglesia fue la institución más poderosa en las esferas pública y privada (Arias, 2003; Beltrán, 2013). A nivel cultural, su hegemonía se tradujo en un nacional-catolicismo en virtud del cual, en un país marcado por la fracturación geográfica y la diversidad de la población, el catolicismo se convirtió en el elemento central de la identidad colombiana de manera que, hasta la mitad del siglo $\mathrm{XX}$, la Iglesia se benefició de un monopolio cultural que no permitió el desarrollo de ideas contrarias ni de sistemas alternativos de creencias (Beltrán, 2013).

Así como sucedió en otros territorios de catolicidad como Francia (Hervieu-Léger, 2003), en Colombia, una de las manifestaciones del poder cultural de esta religión fue la adopción del modelo católico de la familia por el derecho civil. Para entender cómo ese modelo sobrevivió al proceso de laicización del derecho, es necesario remontarse al siglo XIX durante el que se estableció, por primera vez, el matrimonio civil. Así, el 20 de junio de 1853, en el marco del primer proyecto político de secularización de la sociedad, los liberales radicales de la Nueva Granada, votaron la ley "Sobre el matrimonio" mediante la que se estableció el matrimonio civil obligatorio y el divorcio vincular (Artículo 30), incluso por mutuo consentimiento (Artículo 39) (Arias, 2003; Beltrán, 2013; Colmenares, 1997; Hinestrosa, 1974; Jaramillo Sierra, 2013).

Posteriormente, con base en la Constitución de 1853 que permitió la adopción de una forma de Estado federal, algunos estados adoptaron sus propios códigos civiles con distintas reglas en lo relativo al matrimonio, al 
divorcio y a las relaciones paternofiliales. Si bien ninguno puso en duda la desigualdad entre esposas y esposos, algunos adoptaron legislaciones más igualitarias en el campo de las relaciones entre padres e hijos. Así, por ejemplo, el Código Civil del estado de Santander de 1858 no usó la distinción entre hijos naturales y espurios, aceptó la legitimación por reconocimiento en documento o testamento públicos (artículos 12-15), consagró una acción judicial de paternidad extramatrimonial (Artículo 18) y presumió que los hijos de una concubina eran hijos de su compañero sentimental (artículos 113-119) (Jaramillo Sierra, 2013).

Esto significa que, en un primer momento, los liberales radicales construyeron el derecho de familia retomando la lógica del "derecho de principio", proveniente del pensamiento de la Revolución francesa. De acuerdo con esa lógica, los derechos del hombre no deben parar en la puerta de la vida privada. Es decir, la familia no es una entidad lo suficientemente específica como para justificar el no respeto de los derechos fundamentales en el ámbito privado y, por esta razón, el derecho debe asegurar a los individuos el respeto de la igualdad y de la libertad en la vida pública así como en la intimidad (Théry, 1993).

Sin embargo, las reformas liberales en el campo de la familia fueron demasiado avanzadas para la época: al no coincidir con las creencias mayoritarias de las élites, fueron derogadas (Arias, 2003; Aristizábal, 2007).

En efecto, en el campo del régimen matrimonial, una vez aprobada la ley "Sobre el matrimonio", los políticos argumentaron que había que reformarla para ponerla en armonía con las creencias nacionales y "con la decencia pública, o con las costumbres consagradas en este punto por la civilización i por la moral" (Pinzón, 1859, p. 23) según las cuales el matrimonio era un acto sagrado indisoluble y no simplemente un contrato civil fundado exclusivamente en la voluntad de las partes (Aristizábal, 2007; Jaramillo Sierra, 2013).

De hecho, los liberales, en general y, en particular, los ideólogos del liberalismo que defendieron el matrimonio civil y el divorcio vincular como José María Samper o Salvador Camacho Roldán, prefirieron no contraer matrimonio civil ni divorciarse (Bermúdez, 1993; Dueñas, 2002), situación que prueba que, en Colombia, los ideales de la Ilustración, durante el siglo XIX "jamás [llegaron] a concretarse en una forma disidente 
de conciencia religiosa, sino que se [mantuvieron] en la vaguedad del terreno político" (Colmenares, 1997, p. 46) ${ }^{13}$.

En este contexto, tres años después de expedida la ley "Sobre el matrimonio", mediante la Ley del 8 de abril de 1856, el legislador creó un sistema de matrimonio civil facultativo. Así, el Congreso granadino consideró que "el matrimonio es un contrato puramente civil, cuyo arreglo toca exclusivamente a la autoridad temporal". Pero, al mismo tiempo, "como la casi totalidad de los granadinos de hoi (...) miran el matrimonio (...) como un vinculo relijioso, santo, en cuyo arreglo i celebracion solo debe intervenir la Relijion" (Restrepo, 1852), el legislador les otorgó efectos civiles a los matrimonios celebrados por la Iglesia siempre que se registraran ante notario y estipuló que el vínculo matrimonial solo podía disolverse por la muerte de uno de los cónyuges (Aristizábal, 2007; Hinestrosa, 1974; J Jaramillo Sierra, 2013).

La mayoría de estas disposiciones fueron retomadas en el Código Civil de la República de Colombia (Ley 57 de 1887) que, a su vez, retomó el Código Civil de los Estados Unidos de Colombia (Ley 84 de 1873) aunque con algunas "adiciones, supresiones i variaciones"14 (Hinestrosa, 2006; Jaramillo Sierra, 2013).

Al contrario del Código de Napoleón que lo inspiró, el Código Civil colombiano dispuso: i) que los matrimonios celebrados conforme al rito católico eran válidos para todos los efectos civiles y políticos (Artículo 12-L-57/1887); ii) que el divorcio imperfecto no daba lugar a la disolución del vínculo matrimonial pero sí suspendía la vida común de los casados (Artículo 153-L-84/1873); y, iii) que los tribunales eclesiásticos tenían la competencia para anular los matrimonios católicos (Artículo 17-L-57/1887).

13 Rafael Núñez fue el único liberal reconocido que se divorció y que contrajo matrimonio civil en 1877 con Soledad Román, situación que produjo un escándalo social. En efecto, los liberales del Olimpo radical lo consideraron bígamo y, a Soledad Román, su concubina e, incluso, fueron aún más duros que los conservadores. Finalmente, una vez Dolores Gallego, su primera esposa, murió, Rafael Núñez y Soledad Román contrajeron matrimonio católico (Liévano Aguirre, 2013; Otero Muñoz, 1951).

14 La base de la Ley 84 de 1873 fue el Código Civil del estado de Santander de 1870, redactado siguiendo la versión chilena del Código de Napoleón (Hinestrosa, 2006; Jaramillo Sierra, 2013). 
En todo caso, de conformidad con el Código Civil francés, el Código Civil colombiano organizó la familia alrededor del matrimonio, aunque definió esta figura como "un contrato solemne por el cual un hombre i una mujer se unen con el fin de vivir juntos, de procrear i de ausiliarse mutuamente" (Artículo 113-L-84/1873).

Así mismo, le concedió al esposo la patria marital sobre la esposa (artículos 176 y ss.-L-84/1873) y la patria potestad sobre los hijos no emancipados (artículos 288 y ss.-L-84/1873). Adicionalmente, al retomar las categorías de hijos legítimos, legitimados, naturales, incestuosos y adulterinos (artículos 52, 58, 213, 236 y 318-L-84/1873), el Código Civil otorgó un trato diferente a los distintos tipos de hijos, sobre todo en el campo sucesoral (Jaramillo Sierra, 2013).

Cuatro meses después, mediante la Ley 153 de 1887, se reformó el Código Civil para establecer un régimen aún más estricto de la ilegitimidad (Jaramillo Sierra, 2013).

Es decir que, conforme a la primera globalización del derecho que tuvo lugar entre 1850 y 1900, el legislador colombiano reemplazó la lógica del "derecho de principio" por la lógica del "derecho de modelo" en virtud de la cual la teoría de la voluntad no se aplica en el ámbito familiar (Commaille, 2008; Kennedy, 2015; Théry, 1993).

En otras palabras, con base en la creencia en la "excepcionalidad de la familia" (Jaramillo Sierra, 2013), la adopción de la lógica del "derecho de modelo" supuso que la democracia llegó hasta donde empieza la familia, de manera que las relaciones entre esposos y entre padres e hijos fueron reguladas por normas de orden público contrarias a los derechos a la libertad y a la igualdad (Commaille, 2008; Commaille \& Martin, 2014; Giddens, 1993; Théry, 1993).

Desde este punto de vista, aunque la Iglesia se opuso con vigor al matrimonio civil, el modelo católico de la familia pudo sobrevivir, "bajo una forma laicizada", al proceso de secularización formal del derecho (Hervieu-Léger, 2003, p. 182).

Así, por un lado, al concebir la familia como una sociedad irreductiblemente específica por ser el fundamento de los lazos sociales, el derecho civil defendió un único modelo de familia: el de la familia legítima fundada en el matrimonio-institución (Théry, 1993). Entonces, si bien la legislación civil eliminó toda referencia a la ley natural y definió el matrimonio 
como un contrato, terminó por organizar el régimen familiar a partir de las ideas católicas según las cuales la familia es la célula fundamental de la sociedad y se forma, necesariamente, por el matrimonio que tiene varias finalidades: el amor humano entre un hombre y una mujer, la transmisión de la vida a través de la reproducción entre dos sexos complementarios y la educación de los hijos biológicos (Hervieu-Léger, 2003; Portier, 1986, 2011).

Y, por otro lado, al impedir que la autonomía de la voluntad y que la igualdad permearan las relaciones entre esposos y entre padres e hijos, el derecho civil calcó el modelo católico según el cual, como la familia es una institución sometida a la ley natural, los miembros que la conforman no pueden crear, de común acuerdo, las reglas que rigen sus relaciones personales. Al mismo tiempo, al concebir la familia como una estructura orgánica de convivencia regulada por normas de orden público, el derecho civil legitimó la antropología religiosa en tanto hombres y mujeres tienen unos lugares y unos roles específicos y predeterminados que tienen que respetar y cumplir en virtud de su propia naturaleza (Hervieu-Léger, 2003; Portier, 1986; 2011).

Ahora bien, el hecho de que el derecho civil haya retomado el modelo católico de la familia ayudó al catolicismo a mantener su influencia en las sociedades modernas. En efecto, al apoyarse en la idea, validada por el derecho, de que la familia obedece a unas normas de comportamiento que no están sometidas a la voluntad humana, la Iglesia pudo legislar en el ámbito privado gracias a la idea de que la familia se sitúa por fuera de la política, en la esfera del orden de la naturaleza, en la que puede ejercer la competencia que su inspiración divina le asegura sobre las cosas absolutas (Hervieu-Léger, 2003).

De manera más general, la concepción jurídica de la familia como una comunidad que no puede ser regulada por normas creadas por sus propios miembros, le permitió al catolicismo apropiarse del poder simbólico vehiculado por los textos jurídicos para asegurar su propia reproducción institucional e ideológica (Hervieu-Léger, 2003).

Así, desde esta perspectiva, como el derecho legitima ciertas visiones del mundo y deslegitima otras, la adopción del modelo católico de la familia le permitió a esta religión perpetuar y hacer plausible un ejercicio 
de la autoridad "desde arriba", fundado en la idea de que los hombres no pueden gobernarse a sí mismo porque Dios les imprimió una naturaleza determinada que deben respetar para ser considerados verdaderamente humanos (Hervieu-Léger, 2003).

Por estos motivos, el campo de la familia constituyó, hasta hace muy poco tiempo, el último refugio del catolicismo intransigente e integrista en el mundo moderno que acoge la visión de una sociedad estructurada por la lógica democrática (Hervieu-Léger, 2003).

El reconocimiento jurídico del matrimonio entre personas del mismo sexo y del establecimiento de un doble vínculo de filiación materno o paterno constituye una etapa suplementaria, junto con el divorcio, la igualdad entre todos los miembros de la familia y la creación de la unión marital de hecho, del proceso de introducción de la democracia en la sociedad que, gracias al derecho civil, por mucho tiempo, se detuvo en las puertas de la familia (Borrillo \& Fassin, 2001; Commaille \& Martin, 2014; Hervieu-Léger, 2003).

Dicho de otra manera, la apertura del matrimonio y de la filiación a las PMS participa del advenimiento del modelo de la familia relacional fundado en la voluntad de individuos libres e iguales que se unen para buscar su realización personal. Desde este punto de vista, el matrimonio entre personas del mismo sexo y el establecimiento de un doble vínculo de filiación materno o paterno son el arquetipo de las relaciones conyugales y parentales ultramodernas que encuentran su justificación, exclusivamente, en el deseo y en la voluntad, continuamente renovables, de dos individuos que quieren vivir juntos $\mathrm{y}$, tal vez, convertirse en padres (Borrillo \& Fassin, 2001; Commaille \& Martin, 2014; Hervieu-Léger, 2003).

Desde esta perspectiva, el problema para algunos de los militantes estudiados no es tanto que existan homosexuales en pareja o que estos sean padres, sino que dichas situaciones sean legitimadas por el derecho. Así, por ejemplo, para oponerse al reconocimiento jurídico de las PMS, Marta Saíz de Rueda, de la FCVH, allegó a la Corte Constitucional las "Consideraciones acerca de los proyectos de reconocimiento legal de las uniones entre personas homosexuales". En este documento, redactado por la Congregación para la Doctrina de la Fe, se afirma que: 
Se podría preguntar cómo puede contrariar al bien común una ley (...) que se limita a hacer legal una realidad de hecho (...). En este sentido, es necesario reflexionar (...) sobre la diferencia entre comportamiento homosexual como fenómeno privado y el mismo como comportamiento público, legalmente previsto, aprobado y convertido en una de las instituciones del ordenamiento jurídico (...). Las leyes civiles (...) "desempeñan un papel muy importante y a veces determinante en la promoción de una mentalidad y de unas costumbre" (...) Reconocer legalmente las uniones homosexuales o equipararlas al matrimonio, significaría no solamente aprobar un comportamiento desviado y convertirlo en un modelo para la sociedad actual, sino también ofuscar valores fundamentales que pertenecen al patrimonio común de la humanidad. (Expediente D-6362, s.f., pp. 524 a 526, cuaderno 3)

En otras palabras, la causa defendida tiene una dimensión simbólica íntimamente ligada, retomando las palabras de Gusfield, a la dominación, al prestigio o, simplemente, a la supervivencia, en la sociedad global, de cierto estilo de vida (1986, p. 3): aquel que está fundado en los valores morales del catolicismo. Parafraseando a García Villegas y a Dumoulin, esto significa que, para el contramovimiento católico, el derecho es importante porque se trata de un campo social al interior del cual hay que luchar para apropiarse del poder simbólico que vehiculan los textos jurídicos (García Villegas, 2014) de manera que la participación en los mecanismos de producción normativa se convierta en un objetivo esencial para aquellos militantes que quieren que su visión del mundo sea validada por el derecho (Dumoulin, 2010). Al definir lo que es legal, el derecho tiene un efecto sobre lo que es socialmente percibido como aceptable, permitido, normal, posible, etc. (Galanter, 2015; García Villegas, 2014; McCann, 1994).

Al considerar que el derecho tiene una dimensión simbólica que instituye y perpetúa una determinada visión del hombre y del mundo, el activismo católico conservador colombiano se opone, entonces, al reconocimiento jurídico del matrimonio igualitario porque dicho reconocimiento deslegitima la antropología religiosa que se funda en la idea de que el individuo no puede gobernarse a sí mismo porque está afincado en una realidad natural que limita su voluntad. 
Así, por ejemplo, según el vicepresidente del FNF:

[T]oda la vida las personas del mismo sexo han vivido juntas (...). Lo han hecho sin ningún problema (...). El grave problema Icon el matrimonio homosexuall es que tú no puedas crear realidades que no están fundadas en la realidad natural (...). Por eso te decía yo desde el comienzo que todo esto es un proceso de reingeniería social que en el fondo tiene que ver con una reingeniería antropológica (...). En la base de todo esto está precisamente la dinamitación de la antropología filosófica: qué es el ser humano, qué es el hombre (...). ¿Por qué se debate que dos personas del mismo sexo tengan derecho a casarse? Estamos yendo al meollo del asunto. ¿Qué es el hombre? ¿Qué es el ser humano? ¿Es una construcción subjetiva y social o está afincado en una realidad natural que el mismo debe respetar en relación consigo mismo? Es decir, respetar la ley, la norma que está inscrita en él, así como respetamos la ley de la gravedad (...). En mí mismo hay una ley natural que está inscrita en mi cuerpo, en mi biología y que configura mi psique, mi psicología, mi todo, que me hace reconocer que soy un varón, soy un hombre. Está inscrito en mí. (Henao, 2013)

Partiendo de la convergencia entre la doctrina de la ley natural y la biología ${ }^{15}$, el FNF concibe el reconocimiento del matrimonio igualitario como una de las consecuencias de la "ideología de género", concebida como un proyecto de cambio antropológico cuyo propósito es negar que el hombre tiene una naturaleza humana que se expresa en su cuerpo y que limita su voluntad. En el campo de la familia, esa revolución antropológica acarrea no solo la negación de la complementariedad de los dos sexos, sino también la erradicación de la alteridad sexual según la cual los hombres y las mujeres son diferentes. Así, en la medida en que el reconocimiento jurídico del matrimonio entre personas del mismo sexo se funda en el derecho de la no discriminación que equipara la igualdad a la indiferenciación de las parejas según el sexo de sus miembros (Borrillo, 2010; Fondimare, 2014), para el FNF el problema con ese cambio jurídico es que intenta negar la idea católica de que existe una realidad

15 Según el magisterio católico, la naturaleza humana se expresa en el campo de la biología porque los cuerpos vienen sexuados según una configuración binaria que depende de las diferencias anatómicas entre los hombres y las mujeres (Morán Faúndes, 2012b, 2012a). 
natural en virtud de la cual hombres y mujeres son diferentes anatómica, psicológica e intelectualmente.

En efecto, según el vicepresidente del FNF:

De acuerdo con esa teoría [refiriéndose a la ideología de género], supuestamente tú cumples un rol como en el teatro (...). Puedes intercambiar papeles. Eso es lo que dice la ideología de género. El rol, la categoría de femenino y masculino no son más que categorías culturales y subjetivas. Están negando, y esto es lo absurdo, lo insensato de toda esta cuestión, es que niegan la realidad de las cosas que se manifiestan ante nuestros ojos y nuestra razón de que hay hombres y mujeres y de que la biología es una ley natural inscrita en nosotros que afecta y determina nuestra psicología. (Henao, 2013)

Con esto en mente, luchar contra el reconocimiento jurídico del matrimonio igualitario se convirtió en el desafío político más importante para los militantes estudiados y, sobre todo, para la Iglesia católica a nivel global (Béraud E Portier, 2015; Hervieu-Léger, 2003), dado que se interpreta como una de las manifestaciones del proceso de exculturación de esta religión por medio del cual la cultura colectiva -comprendida como el conjunto de las representaciones compartidas por la población, inclusive por los no creyentes- se desliga poco a poco de la matriz cultural católica (Hervieu-Léger, 2003). En otros términos, por causa de este proceso, el catolicismo deja de darle, poco a poco, a las personas las referencias, los valores, los símbolos y las normas que le dan sentido a sus vidas y a experiencias (Hervieu-Léger, 2001).

En Colombia, al menos para una parte de los militantes estudiados y para la jerarquía local, la apertura del matrimonio y de la filiación a las PMS es una de las consecuencias adversas del fenómeno de la globalización por el que fuerzas oscuras y agresivas quieren homogeneizar la población global yendo en contra de la cultura nacional que es, en su mayoría, católica.

En este sentido, un miembro de la Conferencia Episcopal de Colombia, que también hace parte del FNF, manifestó que:

Lo que la Iglesia mira es que hay unos movimientos y unas corrientes hoy en día que están incidiendo muy fuertemente en las legislaciones. Y 
la incidencia en esas legislaciones está llevando a hacer unas leyes que, bueno, no solo miradas desde el punto de vista de la fe, sino miradas desde el punto de vista puramente humano iun momentico! (...). Hay que pensarlo. Sobre todo que también hay que respetar la cultura de nuestro pueblo. Nuestro pueblo tiene unos principios, tiene unos valores. Me refiero por ejemplo a que hay una fuerte presión internacional para que se despenalice totalmente el aborto en Colombia (...). La Iglesia entiende, (...) la jerarquía y los mismos creyentes, sentimos todos que hay unas fuertes presiones, unos fuertes movimientos para legalizar una cantidad de cosas que riñen con los principios, con los valores fundamentales, no solo del evangelio para muchos creyentes, sino de valores que son culturales, que son propios de nuestro pueblo y que hay que respetar. (Restrepo, 2013)

Así mismo, la FCVH considera que las reivindicaciones de igualar jurídicamente a las PMS con las parejas conformadas por un hombre y una mujer son producto de un "cambio de cultura [hecho] a nombre y con el pretexto de la modernización de las instituciones y de los Derechos Humanos" (Dossier D-6362, s.f., p. 525, cuaderno 3). Con base en esa creencia, esta organización se opuso al reconocimiento jurídico de la igualdad entre PMS y parejas conformadas por un hombre y una mujer argumentando que representa a "millones de colombianos que en estos momentos sienten que (...) están siendo atacados los principios y fundamentos en los que se asienta la civilización occidental, al propiciar (...) la introducción de ideologías que en el fondo lo que buscan es destruir el matrimonio, la familia y la vida humana" (Expediente D-6362, s.f., p. 525, cuaderno 3).

Esto significa que algunos de los activistas creen que, en el campo de los derechos fundamentales, organizaciones no gubernamentales, organismos internacionales como la ONU y países del Norte promueven una colonización ideológica ejerciendo presión sobre la Corte Constitucional para cambiar la cultura del pueblo por medio de la imposición de ideologías (como la "teoría del género" o el neoconstitucionalismo) aun cuando la mayoría de los colombianos, al ser católicos, se opone al matrimonio igualitario, a la despenalización del aborto, etc.

Así, por ejemplo, Alejandro Ordóñez Maldonado considera que "el sustento ideológico del derecho a la dosis personal, al suicidio, al 
aborto, a la unión homosexual, a la eutanasia, a la eugenesia, al incesto, a la maternidad incógnita, a la zoofilia, etc." (Ordóñez, 2005, p. 55) es la "ideología del nuevo derecho" que fue creada por "los grandes arquitectos del nuevo orden mundial que mediante tal concepción pretenden la homogeneización compulsiva trasladada al plano espiritual, cultural y jurídico" (Ordóñez, 2005, p. 38).

En este sentido, para el exprocurador existen "planes de dominio universal" para edificar una "aldea global", esto es, "un nuevo orden agnóstico y apátrida, sincrético e irenista (...) en contra de la Civilización Cristiana" que se ha ido imponiendo con la ayuda de "aliados inmejorables o mejor con eficaces instrumentos [como] la sociedad de naciones o naciones unidas (sic) que garantiza la hegemonía planetaria de los nuevos amos del mundo [o como] la UNESCO, organismo (...) que tiene como propósito crear una sola cultural mundial" (Ordóñez, 2005, p. 64). Así, según su punto de vista:

(...) los grandes arquitectos del nuevo orden mundial han diseñado [la] filosofía jurídica [de Nuevo Constitucionalismo] que se impone sin la menor resistencia hasta los últimos rincones de la aldea global, pulverizando todas las creencias, todas las soberanías y todas las tradiciones nacionales mediante el expediente bien conocido en nuestra juridicidad de los bloques de constitucionalidad que hoy hacen parte de la mayoría de los ordenamientos jurídicos. La sociedad global no soporta la afirmación del ser nacional. (Ordóñez, 2005, pp. 64-66)

De manera similar, según varios militantes, el hecho de que el derecho haya dejado de reproducir y validar la antropología católica, es decir, el hecho de que el catolicismo esté en proceso de exculturación, constituye una amenaza para la religión misma.

Así, por ejemplo, para la ACJC, una de las consecuencias del reconocimiento jurídico del matrimonio igualitario es que:

(...) las libertades de pensamiento, conciencia, cultos, catedra y expresión, se[rán] seriamente vulnerados pues toda la filosofía clásica y ética de las principales religiones monoteístas del mundo se[rán] culpables de promover discursos de odio y discriminarorios. Con esto la persecución contra cristianos en Occidente por cuenta de la nueva 
inquisión ser[á] gradual, pero sin duda implacable. (Expediente D-8367 et D-8376 AC., s.f., p. 141, cuaderno 1)

En igual sentido, para el FNF, la apertura del matrimonio a las PMS está íntimamente ligada con el Programa de Educación Sexual y Construcción de Ciudadanía por el que:

(...) se está adoctrinando a nuestros hijos (...) desde los 6 años de edad en la idea de que (...) los niños y adolescentes pueden reclamar ante los padres y el Estado, el derecho a tener relaciones sexuales con quien se desee y como se desee (...). Todos sabemos (...) quiénes están detrás de esta estrategia. Se trata de destruir la familia. ¿Cómo? (...) [V] iolando el derecho constitucional que tenemos los padres de educar a nuestros hijos de acuerdo con nuestros principios y convicciones. (Imprenta Nacional de Colombia, 2013b, p. 20)

En este punto es interesante notar que las preocupaciones de los militantes católicos también son compartidas por la jerarquía católica. En efecto, desde la perspectiva de Aparecida -la V Conferencia General del Episcopado Latinoamericano y del Caribe-, aunque América Latina es un continente que todavía católico en su gran mayoría, el futuro de la religión católica está en peligro en el continente por la implantación de otras iglesias y de nuevos movimientos religiosos que ha acarreado una pérdida de fieles (Consejo Episcopal Latinoamericano, 2007; Levine, 2008) y por "la difusión de una cultura lejana y hostil a la tradición cristiana" que defiende la autodeterminación total del sujeto, sin ningún límite (Consejo Episcopal Latinoamericano, 2007, párr. 10).

La preocupación por la globalización es tan grande que esta conferencia dedicó un capítulo entero a este tema en el que los obispos lamentaron que el patrimonio cultural católico, que permeó las instituciones y las normas sociales y legales, esté siendo atacado por fuerzas culturales agresivas y adversas que provienen del extranjero. En efecto, para los obispos latinoamericanos, la Iglesia ya no produce la cultura: se somete a una nueva que viene del exterior y que la pone en peligro (Consejo Episcopal Latinoamericano, 2007; Levine, 2008). 
Respecto al tema que nos interesa, los obispos afirmaron que la globalización explica el hecho de que las tradiciones culturales católicas ya no se transmitan de generación en generación dentro de la familia, institución que se ha debilitado, entre otras cosas, por "la ideología de género según la cual cada uno puede escoger su orientación sexual, sin tomar en cuenta las diferencias dadas por la naturaleza humana" (Consejo Episcopal Latinoamericano, 2007, párr. 40).

En otras palabras, en Colombia, la lucha para que el derecho retome el modelo católico de la familia está ligado al problema más general de cómo recuperar la hegemonía cultural en un país en el que, si bien la población es todavía mayoritariamente católica, los nuevos movimientos sociales y la globalización le quitaron a la Iglesia católica el monopolio cultural y político gracias al cual, durante mucho tiempo, esa institución pudo ejercer su poder de forma exclusiva (Arias, 2003; Beltrán, 2013; Center for Applied Research in the Apostolate (CARA), 2015; Levine, 2008; 2012).

\section{Conclusiones}

Con el propósito de poner en evidencia la participación de activistas católicos en los asuntos públicos, en este artículo hice un mapeo de los participantes del contramovimiento católico conservador que se movilizaron públicamente ante la Corte Constitucional y/o el Congreso de la República para asegurarse de que el derecho de familia no se desligara del modelo católico de la familia. Así, tal y como lo demostré en la segunda parte, este pudo sobrevivir al proceso formal de laicización del derecho civil construido sobre la idea de que la democracia no puede entrar en el ámbito privado de manera que las relaciones de pareja y entre padres e hijos no deben regularse de conformidad con los derechos a la igualdad y a la libertad.

Adicionalmente, para contribuir a la comprensión de las razones que explican por qué el contramovimiento católico se interesa por la legislación civil relativa a la familia, en la segunda parte de este artículo demostré que, al concebir el derecho como un campo social en el que hay que luchar para apropiarse del poder simbólico que vehiculan 
implícitamente los textos jurídicos (Dumoulin, 2010; García Villegas, 2014), organizaciones de laicos intransigentes y de católicos integristas intervinieron en las arenas judicial y legislativa para asegurarse de que el derecho siguiera legitimando la idea, central para el catolicismo, de que el hombre no puede gobernarse a sí mismo. En este sentido mostré que, para varios militantes católicos, así como para la jerarquía local, el estilo de vida conforme a los valores del catolicismo se encuentra en peligro por causa de la globalización que tiene por objeto exculturar al catolicismo.

\section{Referencias}

Airiau, P. (2000). L'Église et l'Apocalypse: du XIXe siècle à nos jours. París: Berg International Éditeurs.

Airiau, P. (2009). Des théologiens contre Vatican II. 1965-2005. En D. A. Fourcade Michel (Dir.). Un nouvel âge de la théologie? 1965-1980. Colloque de Montpellier juin 2007, (pp. 69-84). París: Khartala.

Albarracín, M. E Lemaitre, J. (2016). Capítulo 4. La cruzada contra el matrimonio entre personas el mismo sexo en Colombia. En M. Sáez \& J. M. Morán Faúndes (Eds.). Sexo, delitos y pecados. Intersecciones entre religión, género, secualidad y el derecho en América Latina, (pp. 92-122). Washington, D. C.: Center for Latin American \& Latino Studies.

Arias, R. (2003). El episcopado colombiano: intransigencia y laicidad 1850-2000. Bogotá, D. C.: Universidad de los Andes.

Aristizábal, M. (2007). Madre y esposa: silencio y virtud: ideal de formación de las mujeres en la provincia de Bogotá, 1848-1868. Bogotá, D. C.: Universidad Pedagógica Nacional.

Avon, D. (2016). Liberté religieuse, liberté de conscience : une mise en perspective historique. Webtv de l'Université de Nantes. Recuperado de http://webtv. univ-nantes.fr/fiche/7830/dominique-avon-liberte-religieuse-liberte-deconscience-une-mise-en-perspective-historique

Beltrán, W. M. (2013). Del monopolio católico a la explosión pentecostal. Pluralización religiosa, secularización y cambio social en Colombia. Bogotá, D. C.: Universidad Nacional de Colombia.

Béraud, C. E Portier, P. (2015). Métamorphoses catholiques. Acteurs, enjeux et mobilisations depuis le mariage pour tous. Nantes: Éditions de la Maison 
des sciences de l'homme. Recuperado de http://www.editions-msh.fr/ livre/?GCOI=27351100093820

Bermúdez, S. (1993). El bello sexo: la mujer y la familia durante el Olímpo Radical. Bogotá, D. C: Ediciones Uniandes.

Blee, K. M. \& Taylor, V. (2002). Semi-Structured Interviewing in Social Movement Research. En B. Klandermans \& S. Staggenborg (Eds.). Methods of Social Movement Research, (pp. 92-117). Minneapolis: University of Minnesota Press.

Borrillo, D. (2010). Le sexe et le Droit: de la logique binaire des genres et la matrice hétérosexuelle de la loi. Meritum, revista de Direito da Universidade FUMEC, 5(2). Recuperado de http://www.fumec.br/revistas/meritum/ article/view/1059

Borrillo, D., E Fassin, É. (2001). Introduction. En D. Borrillo \& É. Fassin (Dirs.). Au-delà du PaCS, (pp. 1-9). París: Presses Universitaires de France. Recuperado de https://www.cairn.info/au-dela-du-pacs--9782130519904.htm

Center for Applied Research in the Apostolate (CARA). (2015). Global Catholicism: Trends \& Forecasts. Washington, D. C.: Georgetown University Press.

Colmenares, G. (1997). Partidos politicos y clases sociales. Santafé de Bogotá: Tercer Mundo S. A.

Commaille, J. (2008). La famille, l'état, le politique: une nouvelle économie des valeurs. Informations sociales, (136), 100-111.

Commaille, J. \& Martin, C. (2014). Les conditions d'une démocratisation de la vie privée. En D. Borrillo \& É. Fassin (Dirs.). Au-delà du Pacs (pp. 61-78). París: Presses Universitaires de France. Recuperado de http://www.cairn. info/resume.php?ID_ARTICLE=PUF_BORRI_2001_02_0061

Comte, B. (1998). L'honneur et la conscience: catholiques français en résistance (19401944). Ivry-Sur-Seine: Editions de l'Atelier.

Conférence des évêques catholiques du Canada. (1993). Reconnaissance des associations catholiques à caractère national. Ottawa: Conférence des évêques catholiques du Canada.

Dalén, A. (2011). El aborto en Colombia. Cambios legales y transformaciones sociales. Bogotá, D. C.: Universidad Nacional de Colombia.

Della Porta, D. \& Diani, M. (2006). Social Movements. An Introduction. Oxford: Blackwell Publishing.

Donegani, J. M. (1993). La liberté de choisir. Pluralisme religieux et pluralisme politique dans le catholicisme français contemporain. París: Presses de Sciences Po.

Dueñas, G. (2002). Matrimonio y familia en la legislación liberal del siglo XIX. Anuario Colombiano de Historia Social y de la Cultura, (29), 167-193. 
Dumoulin, L. (2010). Autour des enjeux d'une ouverture des sciences du politique au droit. Quelques réflexions en guise d’introduction. En J. Comaille, L. Dumoulin E C. Robert (Dirs.). La juridicisation du politique, (pp. 9-26). Issy-les-Moulineaux: LGDJ-Lextenso éd.

Duriez, B. (2000). Introduction. En P. Brechon, B. Duriez \& J. Ion (Dirs.). Religion et action dans l'espace public. Paris: Editions L'Harmattan.

Duriez, B., Fouilloux, E., Pelletier, D. E Viet-Depaule, N. (2005). Les catholiques dans la République 1905-2005. Paris: Les Editions de l'Atelier/ Editions Ouvrières.

Favier, A. (2011). Les mouvements de laïcs jusqúà la définition romaine de I'Action catholique (XIXe). En Compte-rendude la première sécance publique du Groupe de recherches sur I'Action catholique spécialisée. Lyon.

Fondimare, E. (2014). Le genre, un concept utile pour repenser le droit de la nondiscrimination. La Revue des droits de l'homme. Revue du Centre de recherches et d'études sur les droits fondamentaux, (5). https://doi.org/10.4000/revdh.755

Frölich, L. (2002). Les catholiques intransigeants en France. Paris: L'Harmattan.

Galanter, M. (2015). The radiating effects of courts. En K. O. Boyum \& L. Mather (Eds.). Empirical Theories About Courts, (pp. 115-142). New Orleans: Quid Pro Books. Recuperado de https://www.academia.edu/884240/The_radiating_effects_of_courts

García Villegas, M. (2014). La eficacia simbólica del derecho. Bogotá, D. C.: Editorial Debate.

Giddens, A. (1993). The Transformation of Intimacy: Sexuality, Love and Eroticism in Modern Societies. Palo Alto: Stanford University Press.

Goldstone, J. A. (2003). States, Parties, and Social Movements. Cambridge: Cambridge University Press.

Grossman, E. E Saurugger, S. (2012). Les groupes d'intérêt. Action collective et stratégies de représentation. París: Armand Colin.

Gusfield, J. R. (1986). Symbolic Crusade: Status Politics and the American Temperance Movement. Champaign: University of Illinois Press.

Hertzke, A. D. (1988). Representing God in Washington: The Role of Religious Lobbies in the American Polity. Knoxville: University of Tennesse Press.

Hervieu-Léger, D. (2001). Les formes nouvelles de la religiosité. En Y. Michaud (Dir.). Qú est-ce que la culture?, (pp. 115-126). París: Éditions Odile Jacob.

Hervieu-Léger, D. (2003). Catholicisme, la fin d’un monde. Montrouge: Bayard Éditions.

Hervieu-Léger, D. E Champion, F. (2008). Vers un nouveau christianisme? París: Les Editions du Cerf. 
Hinestrosa, F. (1974). Concordato, matrimonio y divorcio. Bogotá, D. C.: Ediciones Tercer Mundo.

Hinestrosa, F. (2006). El Código Civil de Bello en Colombia. Revista de Derecho Privado, (10), 5-27.

Jaramillo, I. C. E Alfonso, T. (2008). Mujeres, cortes y medios: la reforma judicial del aborto. Bogotá, D. C.: Siglo del Hombre Editores y Universidad de los Andes. Jaramillo Sierra, I. C. (2013). Derecho y familia en Colombia: historias de raza, género y propiedad (1540-1980). Bogotá, D. C.: Universidad de los Andes.

Kennedy, D. (2015). Tres globalizaciones del derecho y del pensamiento jurídico, 18502000. Bogotá, D. C.: Universidad Externado de Colombia.

Kitschelt, H. (1989). The Logics of Party Formation: Ecological Politics in Belgium and West Germany. Ithaca: Cornell University Press.

Kriesi, H. (2015). Party Systems, Electoral Systems and Social Movements. Forthcoming, 1-21.

Krishnan, J. E Dulk, K. (2014). So Help Me God: A Comparative Study of Religious Interest Group Litigation. Georgia Journal of International E Comparative Law, 30(2), 233.

Latala, R. E Rime, J. (2009). Liberté religieuse et Église catholique: héritage et développements récents. Friburgo: Academic Press Fribourg.

Lefebvre, S., Béraud, C. E Meunier, E. M. (2015). Introduction. Les apports théoriques du présent ouvrage. En S. Lefebvre, C. Béraud E E. M. Meunier (Dirs.). Catholicisme et cultures. Regars croisés Québec-France, (pp. 1-20). Québec: Presses de l’Université de Laval.

Lehoucq, E. (2017). Legal Threats and the Emergence of Conservative Legal Mobilization: The Case of Colombia. Working paper.

Lemaitre, J. (2012). By reason alone: Catholicism, constitutions, and sex in the Americas. ICON, 10(2), 493-511.

Lemaitre Ripoll, J. (2010). Anticlericales de nuevo. La Iglesia católica como un actor político ilegítimo en materia de sexualidad y reproducción en América Latina. En Varios Autores. Derecho y sexualidades, (pp. 287-304). Buenos Aires: Libraria Ediciones.

Lemaitre Ripoll, J. (2013). Laicidad y resistencia. México, D. F.: Instituto de Investigaciones Jurídicas de la UNAM.

Levine, D. H. (2008). El futuro visto desde Aparecida. Revista de Artes y Humanidades UNICA, 9(21), 175-196.

Levine, D. H. (2012). Politics, Religion E Society in Latin America. Boulder: Lynne Rienner Publishers, Inc. 
Liévano Aguirre, I. (2013). Rafael Núñez. Bogotá, D. C.: Penguin Random House Grupo Editorial Colombia.

Luck, S. E Dechezelles, S. (2015). Introduction. Mondes mouvementistes et partisans: points de contact, passerelles et pistes d'exploration. En S. Luck E S. Dechezelles (Dirs.). Voix de la rue ou voie des urnes?: Mouvements sociaux et partis politiques, (pp. 9-28). Rennes: Presses universitaires de Rennes. Recuperado de http://books.openedition.org/pur/24909

Malagón Penen, L. (2015). Movimiento LGBT y contramovimiento religioso en Colombia. Brazilian Journal of Empirical Legal Studies, 2(1), 162-184.

Martínez, A. (2002). La evangelización de la política. Los laicos. Destinatarios y protagonistas de la Política. Tunja: Imprenta Muisca LTDA.

Mayeur, J. M. (1972). Catholicisme intransigeant, catholicisme social, démocratie chrétienne. Annales. Économies, Sociétés, Civilisations, 27(2), 483-499.

McCann, M. (1994). Rights at Work. Chicago: The University of Chicago Press. Recuperado de http://www.press.uchicago.edu/ucp/books/book/chicago/R/ bo3630053.html

Médevielle, G. (2009). La loi naturelle selon Benoît XVI. Études, Tome 410(3), 353-364.

Meyer, D. S. E Tarrow, S. G. (1998). The Social Movement Society: Contentious Politics for a New Century. Lanham: Rowman E Littlefield.

Michel, F. (2009). Intégrisme catholique et politique. Études, Tome 411(9), 211-222.

Michel, F. E Sesboüé, B. (2009). De Mgr Lefebure à Mgr Williamson : Anatomie d'un schisme. París: Lethielleux/Desclée de Brouwer. Recuperado de https:// www.amazon.fr/De-Mgr-Lefebvre-Williamson-Anatomie/dp/2283610613

Morán Faúndes, J. M. (2012a). El activismo católico conservador y los discursos sobre sexualidad: cartografía de una ciencia heterosexual. Sociedad y Religión: Sociología, Antropología e Historia de la Religión en el Cono Sur, XXII(37), 167-205.

Morán Faúndes, J. M. (2012b). Sexualidad y alteridad: argumentos del conservadurismo religioso cordobés contra el matrimonio "igualitario". Soc. et Cult., Goiânia, 15(2), 347-358.

Moyn, S. (2015). Christian Human Rights. Philadelphia: University of Pennsylvania Press.

Otero Muñoz, G. (1951). La vida azarosa de Rafael Núñez, un hombre y una época. Bogotá, D. C.: Editorial ABC.

Pelletier, D. E Schlegel, J. L. (2012). À la gauche du Christ. Les chrétiens de gauche en France de 1945 à nos jours. París: Editions du Seuil.

Portier, P. (1986). La philosophie politique de l'Église catholique: changement ou permanence? Revue française de science politique, 36(3), 325-341. 
Portier, P. (2005). L'Église catholique face au modèle français de laïcité. Archives de sciences sociales des religions, (129), 117-134.

Portier, P. (2011). La pensée catholique de la famille. Réflexions autour de la rénovation wotylienne. En M. Gross, S. Mathieu \& S. Nizard (Dirs.). Sacrées familles! Changements familiaux. Changements religieux, (pp. 212-227). Toulouse: Éditions Érès.

Poulat, É. (1977). Église contre bourgeoisie: introduction au devenir du catholicisme actuel. Tournai: Casterman.

Poulat, É. (1980). Une Église ébranlée: changement, conflit et continuité de Pie XII à Jean-Paul II. Tournai: Casterman.

Poulat, É. (1982). Modernistica. Horizons, physionomies, débats. París: Nouvelles Editions Latines.

Poulat, É. (1986). L'Église ć est un monde. Lyon: Les Editions du Cerf.

Sandoval Rojas, N. (2015). Movilizarse ante la Corte: trayectoria y efectos de tres episodios de movilización legal constitucional de feministas, indigenas y víctimas de crimenes de Estado en Colombia. Bogotá, D. C.: Universidad de los Andes. Sawicki, F. (2015). 1. Partis politiques et mouvements sociaux: des interdépendances aux interactions et retour... En S. Dechezelles \& S. Luck (Eds.). Voix de la rue ou voie des urnes?: Mouvements sociaux et partis politiques, (pp. 31-45). Rennes: Presses universitaires de Rennes. Recuperado de http:// books.openedition.org/pur/24911

Smith, C. (1996). Disruptive Religion: The Force of Faith in Social Movement Activism. Nueva York: Routledge.

Theobald, C. (2009). La différence chrétienne. Études, Tome 412(1), 65-76. Théry, I. (1993). Le démariage: justice et vie privée. París: Éditions Odile Jacob. Tilly, C. E Tarrow, S. (2008). Politique(s) du conflit. París: Presses de Sciences Po. Vaggione, J. M. (2005a). Dios y la ley. Las influencias religiosas en el derecho. Anuario del Centro de Investigaciones Jurídicas y Sociales, VIII, 505-514.

Vaggione, J. M. (2005b). Reactive Politization and Religious Dissidence: The Political Mutations of the Religious. Social Theory and Practive, 31(2), 233-255. Vaggione, J. M. (2009a). La religión en el derecho. La Iglesia católica frente al reconocimiento legal de las parejas del mismo sexo. En Comisión 10. Derecho, Género y Sexualidad, (pp. 1-16). Córdoba.

Vaggione, J. M. (2009b). La sexualidad en un mundo postsecular. El activismo religioso y los derechos sexuales y reproductivos. En M. S. Gerlero (Comp.). Derecho a la sexualidad, (capítulo V). Buenos Aires: Editorial David Grinberg Libros Jurídicos. 
Waché, B. (2004). Militants catholiques de rOuest. De raction religieuse aux nouveaux militantisme, XIXe-XXe siècle. Rennes: Presses Universitaires de Rennes.

Willaime, J. P. (2012). Conclusion. En C. Béraud, F. Gugelot \& I. Saint-Martin (Dirs.). Catholicisme en tensions, (pp. 309-311). París: Editions de l'Ecole des Hautes Etudes en Sciences Sociales.

\section{Otros}

ACJC. (2013, enero 30). Asociación Colombiana de Juristas Católicos. Recuperado el 1 de abril de 2014, de http://juristascatolicos.blogspot.com/2013/01/ iv-congreso-internacional-de-juristas.html

Cámara de Comercio de Bogotá. (2014a, marzo 3). Certificado de existencia y representación legal de Asociación Colombiana de Juristas Católicos, ACJC.

Cámara de Comercio de Bogotá. (2014b, marzo 3). Certificado de existencia y representación legal de Fundación Cultura de la Vida Humana.

Cámara de Comercio de Bogotá. (2014c, marzo 3). Certificado de existencia y representación legal de Laicos por Colombia.

CathoJuris. (2005, febrero 6). L'Union Internationale des Juristes Catholiques Présentation. Recuperado de http://cathojuris.org/article37.html

Código de Derecho Canónico. (2017). Recuperado de http://www.vatican.va/ archive/ESL0020/_P10.HTM

Congrégation pour la doctrine de la foi. (2002, noviembre 24). Note doctrinale concernant certaines questions sur l'engagement et le comportement des catholiques dans la vie politique. Recuperado el 15 de septiembre de 2015 de http://www.vatican.va/roman_curia/congregations/cfaith/documents/ rc_con_cfaith_doc_20021124_politica_fr.html\#_ftnref19

Consejo Episcopal Latinoamericano. (2007, marzo 31). V Conférence générale de l'épiscopat latino-américain et des Caraïbes. Aparecida.

Consejo Nacional de Laicos de Colombia. (s.f.). CNL Consejo Nacional de Laicos. Por un laicado colombiano unido y organizado. Recuperado el 4 de septiembre de 2014 de http://www.consejonacionaldelaicos.org/

Expediente D-6362. (s.f.). Acción pública de inconstitucionalidad contra los articulos 1 y 2 de la Ley 54 de 1990. Actor: Marcela Sánchez Buitrago y otros. (cuaderno 1: 257 pp.; cuaderno 2: 520 pp.; cuaderno 3: 609). Corte Constitucional. Expedientes D-8367 y D-8376 AC. (s.f.). Acción pública de inconstitucionalidad contre el Artículo 113 del Código Civil. Actor: Carlos Andrés Echeverry Restrepo 
$y$ otros (cuaderno 1: 276 pp.; cuaderno 2: 568 pp.; cuaderno 3: 176 pp.; cuaderno 4: 22 pp.; cuaderno 5: 24 pp.). Corte Constitucional.

Fundación Cultura de la Vida Humana. (s.f.). Fundación Cultura de la Vida Humana. Recuperado el 12 de febrero de 2018 de http://fundacionculturadelavidahumana.org/equipo.html

Fundación Derecho a Nacer. (s.f.). Fundación Derecho a Nacer - Andrés Forero Medina. Recuperado el 13 de febrero de 2018 de http://fundacionderechoanacer.org/andres-forero-medina

Gaudium Press. (2010, enero 22). Consejo Nacional de Laicos de Colombia realizará seminario sobre Caritatis in Veritate. Recuperado el 13 de febrero de 2018 de http://es.gaudiumpress.org/content/12841-Consejo-Nacionalde-Laicos-de-Colombia-realizara-seminario-sobre-Caritas-in-Veritate

Henao, L. C. (2013, mayo). Entrevista a Luis Carlos Henao de Brigard, fundador y director del Foro Nacional de la Familia.

Human Life International. (s.f.). Our Mission. Recuperado el 28 de agosto de 2015 de http://www.hli.org/about-us/our-mission/

Imprenta Nacional de Colombia. (2013a). Gaceta del Congreso, (86), 60.

Imprenta Nacional de Colombia. (2013b). Gaceta del Congreso, (389), 40.

Lefebvre, M. (1976). Jaccuse le Concile (Fraternité Sacerdotale Saint-Pie X). http:// www.fsspx.org/fr/category/bibliotheque-mediatheque/jaccuse-le-concile/.

Lefebvre, M. (1987). Ils ron découronné. Du libéralisme à Tapostasie. La tragédie conciliaire. París: Editions Fideliter.

Opus Dei. (2015, octubre 27). Cronología del Opus Dei. Recuperado el 26 de octubre de 2015 de http://opusdei.org.co/es-co/article/cronologia-delopus-dei/

Ordóñez, A. (2005, febrero 4). El nuevo derecho, el nuevo orden mundial y la revolución cultural. I Foro Internacional Universitario Identidad y legado histórico.

Pinzón, C. (1859, enero 1). Exposición del secretario de Estado del despacho de Gobierno de la Nueva Granada al Congreso Constitucional de 1859. Imprenta del Estado.

Restrepo, J. (2013, mayo). Entrevista con el padre Jaime Restrepo, director del departamento de matrimonio y familia de la Conferencia Episcopal de Colombia y miembro del Foro Nacional de la Familia.

Restrepo, V. (1852, abril 8). Informe de la comisión de la Cámara de Representantes sobre el proyecto de lei sobre matrimonio. El Catolicismo, pp. 65-66. Suárez, J. (2013, noviembre). Entrevista con Javier Suárez, fundador y representante legal de la Fundación un Hombre y una Mujer. 
Vatican II. (1964, noviembre 21). Lumen gentium. Recuperado de http:// www.vatican.va/archive/hist_councils/ii_vatican_council/documents/vatii_const_19641121_lumen-gentium_sp.html

Vatican II. (1965, diciembre 7). Gaudium et spes. Recuperado el 15 de septiembre de 2015 de http://www.vatican.va/archive/hist_councils/ii_vatican_council/ documents/vat-ii_const_19651207_gaudium-et-spes_fr.html 
